\title{
Review Article \\ Overview of Celiac Disease in Russia: Regional Data and Estimated Prevalence
}

\author{
Lyudmila V. Savvateeva, ${ }^{1}$ Svetlana I. Erdes, ${ }^{2}$ Anton S. Antishin, \\ and Andrey A. Zamyatnin Jr. ${ }^{1,3}$ \\ ${ }^{1}$ Institute of Molecular Medicine, Sechenov First Moscow State Medical University, Moscow 119991, Russia \\ ${ }^{2}$ Faculty of Pediatrics, Sechenov First Moscow State Medical University, Moscow 119991, Russia \\ ${ }^{3}$ Belozersky Institute of Physico-Chemical Biology, Lomonosov Moscow State University, Moscow 119992, Russia \\ Correspondence should be addressed to Andrey A. Zamyatnin Jr.; zamyat@belozersky.msu.ru
}

Received 29 November 2016; Revised 15 January 2017; Accepted 30 January 2017; Published 20 February 2017

Academic Editor: David Bernardo

Copyright (C) 2017 Lyudmila V. Savvateeva et al. This is an open access article distributed under the Creative Commons Attribution License, which permits unrestricted use, distribution, and reproduction in any medium, provided the original work is properly cited.

Celiac disease $(C D)$ is an autoimmune enteropathy triggered by the ingestion of dietary gluten from some cereals mainly in individuals carrying the HLA-DQ2 and/or HLA-DQ8 haplotypes. As an autoimmune disease, CD is manifested in the small intestine in the form of a progressive and reversible inflammatory lesion due to immune response to self-antigens. Indeed, CD is one of the most challenging medicosocial problems in current gastroenterology. At present, the global CD prevalence is estimated at approximately $1 \%$ based on data sent from different locations and available CD screening strategies used. However, it is impossible to estimate global CD prevalence without all the data from the world, including Russia. In this review, we summarize the data on the incidence and prevalence of CD across geographically distinct regions of Russia, which are mostly present in local Russian scientific sources. Our conclusion is that the situation of CD prevalence in Russia is higher than is commonly believed and follows global tendencies that correspond to the epidemiologic situation in Europe, America, and Southwest Asia.

\section{Introduction}

Celiac disease (CD) is an autoimmune-based disorder triggered by ingested gluten-containing grains in genetically predisposed individuals [1]. CD patients have a wide range of both gastrointestinal (chronic diarrhea with weight loss and malabsorption) and nonintestinal (e.g., iron-deficiency anemia, osteoporosis, and "autoimmune" conditions) symptoms revealing typical and atypical forms of CD. CD can be identified at any age and in both genders or stay undiagnosed. In recent years, considerable changes in the epidemiology of worldwide CD have been observed, and the development of proper screening tests has led to estimations of its incidence.

CD pathogenesis involves the adaptive (HLA molecules, transglutaminase 2, dendritic cells, and CD4(+) T-cells) and the innate immunity with an IL-15-mediated response elicited in the intraepithelial compartment. Currently, the only treatment is a permanent strict gluten-free diet (GFD) [2]. However, some cereals are an important source of proteins, lipids, vitamins, minerals, and fibre, and their inclusion in a gluten-free diet might improve the nutritional status of celiac patients but the immunogenicity of certain grain cultivars should be thoroughly tested $[3,4]$. Since CD is a common and lifelong disorder, many studies have focused on the intensive development of drugs for the treatment of gluten intolerance [5]. Medical treatment will significantly improve the quality of life of patients with gluten-related diseases by allowing a nonstrict gluten-free diet.

Since CD is the result of both environmental and genetic factors the world population distribution of CD is determined by gluten consumption and mainly class II human leukocyte antigens (HLA) genes (HLA-DQ2, HLA-DQ8). On this basis, it is evident that gluten intolerance is more common in Europe, South and North Americas, Australia, Southwest Asia, and North Africa and less common in the Far East. This is confirmed by the recent increase in large-scale populationbased studies (see Lionetti et al. [6] for a review). Research indicates that the $\mathrm{CD}$ prevalence is approximately $1 \%$ of the 


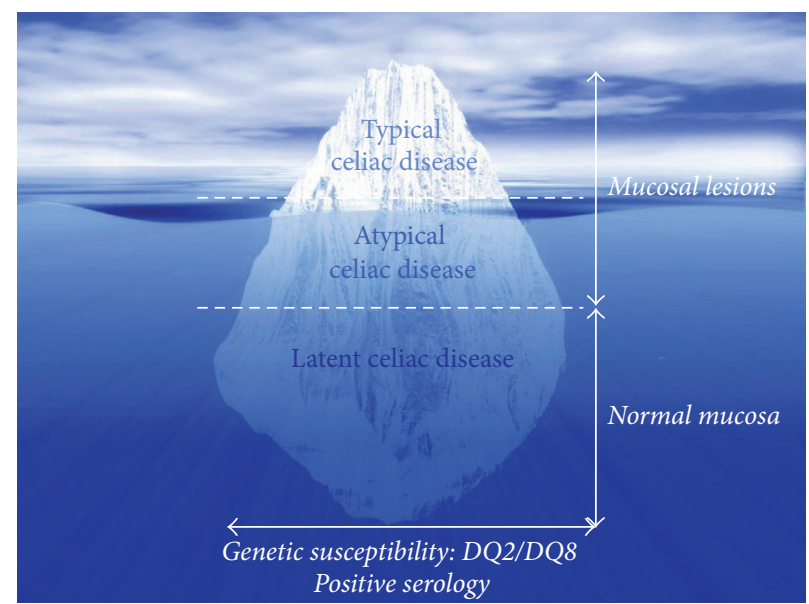

Figure 1: The celiac iceberg (adapted from Catassi et al. [8] and Fasano and Catassi [9]).

general population, with variations being due to the high rate of hidden and atypical forms of the disease.

In general, the display of epidemiological changes of CD can be represented by the "iceberg" model, originally proposed by Logan [7] and later promoted by Catassi and Fasano (Figure 1) $[8,9]$. Thus, it was suggested that the total size of the "iceberg" is more or less the same worldwide, although the "waterline" (the ratio of diagnosed to undiagnosed cases) may dynamically shift depending on the region and population as well as clinician awareness, availability of diagnostic tools, and the degree of clinical manifestations of the disease and so forth [9]. This clarifies some divergences in the results of discrete population studies.

The worldwide distribution of CD cannot be reliable without data from Russia, which occupies one-sixth of the global land area. Thus, the aim of this review is to present the data available on CD epidemiology in Russia and to generate preliminary insight into this common chronic enteropathy.

\section{CD Diagnosis and Screening Strategies}

CD can be diagnosed according to the current guidelines following certain criteria, for example, updated algorithms of (i) the European Society for Pediatric Gastroenterology, Hepatology and Nutrition (ESPHGAN), (ii) North American Society for Pediatric Gastroenterology, Hepatology and Nutrition (NASPGHAN), (iii) World Gastroenterology Organization (WGO-OMGE), (iv) British Society of Gastroenterology, and (v) American College of Gastroenterology [10-13]. Updated algorithms following major global guidance were also recommended for use in Russia [14]. The progress in the development of immunobiological and genetic laboratory tests screening associated with $\mathrm{CD}$ and gastrointestinal endoscopic techniques led to an increased CD frequency detection in patients with both typical and atypical (asymptomatic) clinical courses. Besides, it is possible to detect the disease in at-risk groups, which is comprised of persons with genetic predisposition, relatives of CD patients, people with irondeficiency anemia, premature osteoporosis and osteopenia, type 1 diabetes mellitus, autoimmune thyroid disease, liver disease, Down syndrome, or Turner's syndrome, and patients suffering from some other diseases [15]. Some researchers suggest that the timely detection of $\mathrm{CD}$ in at-risk groups and subsequent treatment can reduce the severity of $C D$ complications $[16,17]$.

Genetic susceptibility in $\mathrm{CD}$ is linked to HLA genes DQ2 and DQ8, namely, HLA-DQA1 ${ }^{*}$ 05-DQB1 ${ }^{*} 02$ (DQ2) and DQA1 ${ }^{*} 03-\mathrm{DQB1}{ }^{*} 0302$ (DQ8) [18]. The identification of additional disease genes is a research subject for the celiac genetic community. It has been revealed that $\mathrm{CD}$ is associated with genes of non-HLA-region $[19,20]$; however, it is still believed that $\mathrm{CD}$ is unlikely in the absence of the alleles encoding the DQ2 and DQ8 [21].

Screening for CD signs is provided by the use of serologic antibody-based tests (Table 1), which are in most enzymelinked immunosorbent assays (ELISA). Currently, the optimal diagnostic kits for CD are IgA anti-tTG2- (IgA antitissue transglutaminase 2-) based ELISA and IgA AEA- (IgA anti-endomysial antibodies-) based IFA (detected by indirect immunofluorescence assay) due to their high sensitivity and specificity and reliability [22]. However, some studies described below still use outdated methodology for the serologic detection of anti-gliadin antibodies (IgA AGA, IgG AGA). This methodology is not currently recommended for $\mathrm{CD}$ diagnosis due to the low positive predictive value compared to other available serological tests [22].

The values of serological antibody screening tests have long been recognized in preselecting patients for small intestinal biopsy diagnosis. Intestinal biopsy is considered as the "gold standard" for the diagnosis of CD. For instance, small-bowel mucosal villous atrophy and crypt hyperplasia detection remain a central test in CD diagnosis (Table 1), and an increase of intraepithelial lymphocytes may indicate latent $\mathrm{CD}$ [15]. The grading of morphological alternations according to the Marsh-Oberhuber classification is widely used in Russia to diagnose CD [23].

Decisions on screening for CD should be carefully considered. Persons from at-risk groups are usually involved in these studies (case-finding process). However, this strategy is 
TABLE 1: CD screening (in patients with manifestation of clinical symptoms).

\begin{tabular}{|c|c|c|c|c|c|c|c|}
\hline & \multicolumn{3}{|c|}{ Serology (serologic markers) ${ }^{*}$} & \multicolumn{3}{|c|}{$\begin{array}{l}\text { Endoscopy of duodenum (mucosal } \\
\text { morphologic alternations }{ }^{* *} \text { ) }\end{array}$} & $\begin{array}{l}\text { Genotype (genetic } \\
\text { markers) }\end{array}$ \\
\hline & \multicolumn{3}{|c|}{$\begin{array}{l}\text { IgA anti-tissue transglutaminase } \\
\text { antibodies (IgA anti-tTG, IgG anti-tTG } \\
\text { antibodies) }\end{array}$} & \multicolumn{3}{|l|}{ Mucous membrane thickness } & \\
\hline & \multicolumn{3}{|c|}{$\begin{array}{l}\text { Anti-endomysial antibodies (AEA, } \\
\text { IgA-anti-EMA) }\end{array}$} & \multicolumn{3}{|l|}{ Villus height } & HLA-typing \\
\hline & \multirow{2}{*}{\multicolumn{3}{|c|}{$\begin{array}{l}\text { Anti-deamidated gliadin peptide (IgA } \\
\text { anti-DGP, IgG anti-DGP) }\end{array}$}} & \multicolumn{3}{|l|}{ Crypt depth } & \\
\hline & & & & \multicolumn{3}{|l|}{ Crypt-villus ratio } & \\
\hline Limitations & \multicolumn{3}{|c|}{$\begin{array}{l}\text { Specificity and sensitivity of test method; } \\
\text { the active period of the disease; } \\
\text { long-term gluten-free diet }\end{array}$} & \multicolumn{3}{|c|}{$\begin{array}{l}\text { Similar histological pattern of some other } \\
\text { diseases; long-term gluten-free diet }\end{array}$} & - \\
\hline \multirow{2}{*}{\multicolumn{8}{|c|}{$\begin{array}{l}\text { *Some studies described in the current review still used outdated methodology for the serologic detection of Ig } \\
{ }^{* *} \text { These criteria are particularly used for the diagnosis of CD, according to Marsh-Oberhuber classification [2 } \\
\text { TABLE 2: CD incidence rate per the region population. }\end{array}$}} \\
\hline & & & & & & & \\
\hline Region & Year & Age group & $\begin{array}{l}\text { Sex ratio } \\
(\mathrm{m} \% / \mathrm{f} \%)\end{array}$ & Screening test & Biopsy & $\mathrm{CD}(\%)$ & Author \\
\hline Arkhangelsk region & 2005 & $\begin{array}{l}\text { Children (6 mths-18 yrs; } \\
\quad<7 \text { yrs, 54\%) }\end{array}$ & $60.0 / 40.0$ & Anti-tTG and/or AEA & Yes & $0.02 \%$ & Smirnova et al. [57] \\
\hline Chelyabinsk & 2004 & Children (0-18 yrs) & ND & $\begin{array}{l}\text { AGA and/or anti-tTG } \\
\text { and/or AEA }\end{array}$ & Yes & $0.02 \%$ & $\begin{array}{l}\text { Turchina and Tabak } \\
\text { [58] }\end{array}$ \\
\hline $\begin{array}{l}\text { Sakha Republic } \\
\text { (Yakutia) }\end{array}$ & 2008 & Children (6 mths-18 yrs) & $48.4 / 51.6$ & Anti-tTG & Yes & $0.06 \%$ & Savvina et al. [59] \\
\hline Saint Petersburg & $\begin{array}{c}1999- \\
2002\end{array}$ & Children (6 mths-18 yrs) & $50.0 / 50.0$ & Anti-tTG and/or AEA & Yes & $0.02 \%$ & Vasilkova [60] \\
\hline Sverdlovsk region & 2009 & Children (0-18 yrs) & ND & $\begin{array}{l}\text { AGA and/or anti-tTG } \\
\text { and/or AEA }\end{array}$ & Yes & $0.30 \%$ & Klimin et al. [61] \\
\hline Tomsk region & 2010 & $\begin{array}{l}\text { Children (mean age } \\
8.6 \pm 0.6)\end{array}$ & $50.5 / 49.5$ & Anti-tTG and/or AEA & Yes & $0.05 \%$ & Yankina $[62]$ \\
\hline Yakutsk & 2008 & $\begin{array}{l}\text { Children (6 mths-17 yrs; } \\
<4 \text { yrs, } 8.7 \% \text {; } 5-7 \text { yrs, } 28.8 \% \text {; } \\
8-10 \text { yrs, } 25.0 \% ; 11-14 \text { yrs, } \\
26.3 \% ; 15-17 \text { yrs, } 11.2 \%)\end{array}$ & $65.0 / 35.0$ & Anti-tTG and/or AEA & Yes & $0.11 \%$ & Savvina et al. [63] \\
\hline
\end{tabular}

ND: not determined.

ineffective for detecting undiagnosed CD in the wider population. In contrast, mass screening is extremely expensive and depends on a number of assumptions. Thus, it is considered that efficient screening CD programmes might be carried out by testing school-age children [24].

\section{Present Epidemiologic Data on CD in Russia}

Until recently, celiac disease in Russia has been considered as a rare disease with a frequency of 1 to 5 per 10,000 persons, but, as elsewhere, the advance in $\mathrm{CD}$ diagnosis has changed this, leading to the identification of various forms of $\mathrm{CD}$ (or gluten intolerance). Thus, the growing incidence rate, when compared with the population of the whole region, has revealed that $\mathrm{CD}$ prevalence in Russia has increased from about $0.02 \%$ to $0.30 \%$ (Table 2 ).

Massive studies on CD prevalence in Russia have not yet been carried out, and the only detailed study presented in the international scientific literature was focused on CD prevalence in Karelia [25]. In this study, the frequency of biopsy-proven $\mathrm{CD}$ was reported as 1:496. In addition, a number of local publications can be found [26, 27], which are only available in Russian. These reports contain scattered data from different regions of Russia (Figure 2), with the CD prevalence varying from $0.20 \%$ to $0.57 \%$ in the general population and up to $15.98 \%$ in specific risk patient groups (patients from specialized gastrointestinal clinics who are suffering from chronic diarrhea, other manifestations of enteropathy, iron-deficiency anemia of unknown genesis, type 1 diabetes mellitus, autoimmune thyroid disease, etc.) (Table 3).

Epidemiological studies were also conducted in two CIS (Commonwealth of Independent States) countries: Kazakhstan and Uzbekistan. Thus in Almaty, Kazakhstan (as a "reflection" of the demographic situation in Kazakhstan, in general), CD prevalence among children was found as 1:262 


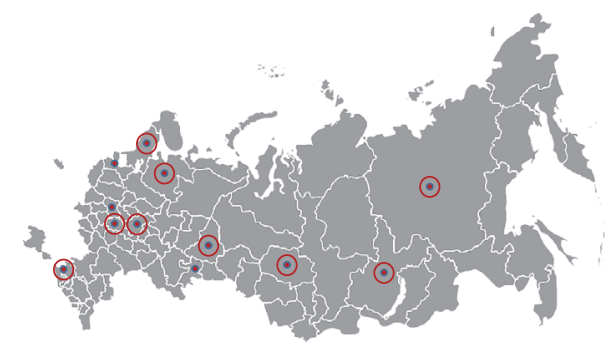

FIGURE 2: Geographic distribution of incidence reports and prevalence studies on CD in Russia. Small circles indicate that the data were only obtained from the regional center. Rounded circles indicate that the data were collected from several locations within the region. See Tables 2 and 3 for the results of these studies.

$(0.38 \%)$ with the $1: 5$ ratio of typical to atypical CD forms [28]. According to the Pediatric Research Institute of the Republic of Uzbekistan (Tashkent region) the CD incidence was 1:366 $(0.27 \%)$ [29].

Studies on polymorphic variants of CD susceptibility alleles HLA-DQ2 and/or HLA-DQ8 in CD patients using HLA SSP typing have been conducted in several regions of Russia (75 subjects in Tomsk, 32 subjects in Krasnodar, and 17 subjects in Yakutia [30-32]) and in Kazakhstan (72 CD patients in Almaty [28]). These studies report that $76.9 \% \mathrm{CD}$ patients in Tomsk, $81.2 \%$ CD patients in Krasnodar, and 80.9\% CD patients in Yakutia carry HLA-DQ2 and/or HLA-DQ8 [30-32]. Thus, in CD patients from Tomsk and Krasnodar the presence of 8 allelic variants for HLA-DQA1 loci and 12 allelic variants for HLA-DQB1 loci was screened. The most frequent alleles detected among CD patients in Krasnodar were DQA1*0501 (40.6\%), DQA1*0201 (21.9\%), and DQB1* 0201 (35.9\%), whereas the most frequent allele reported for patients from Tomsk was DQA1*0501 (37.3\%) [30,31]. Three-locus HLA haplotype screening (DRB1, DQA1, and DQB1) was performed in CD patients from Yakutia. In this study, the following haplotype frequencies were detected: $30 \%$ for $\mathrm{DRB}^{*} 04 / \mathrm{DQA} 1{ }^{*} 0301 / \mathrm{DQB} 1^{*} 0302,30 \%$ for $\mathrm{DRB}^{*}$ 03/DQA1 ${ }^{*} 0501 / \mathrm{DQB1}{ }^{*} 0201,25 \%$ for $\mathrm{DRB}^{*} 07 /$ $\mathrm{DQA}^{*}{ }^{*} 0201 / \mathrm{DQB} 1{ }^{*} 0202$, and $15 \%$ for $\mathrm{DRB} 1^{*} 11 / \mathrm{DQA} 1{ }^{*} 05-$ $05 / \mathrm{DQB1}{ }^{*} 0301$ [32]. In Kazakhstan the presence of HLADQ2 and/or HLA-DQ8 was identified even less frequently then in the regions of Russia and was found only in $60.2 \%$ of the samples obtained from CD patients [28]. Thus, the screening of CD susceptibility HLA alleles in Kazakh patients showed the following haplotype frequencies: $26.4 \%$ for $\mathrm{DQA}^{*} 0501$ and DQB1 ${ }^{*} 0201,34.7 \%$ for $\mathrm{DQA} 1^{*} 0501$ or DQB1 ${ }^{*} 0201$, and $8.3 \%$ for $\mathrm{DQA}^{*} 0301$ and $\mathrm{DQB1}{ }^{*} 0302$. Furthermore, the authors suggest pointing special attention on the availability of $\mathrm{DRB} 1^{*} 10$ allele in CD patients, the frequency of which was detected as $15.3 \%$ [28].

\section{Discussion}

In addition to the one detailed study focusing on the CD prevalence in Russia that has been published in the international scientific literature [25], several reports from geographically distinct regions on the topic can be found in local
Russian scientific literature (summarized in Tables 2 and 3). These studies include reports on incidence rate and reports on CD screenings, most of which were performed in specific risk groups. However, the design of these studies and arsenal of diagnostic tools used for CD diagnosis, in some cases, varies considerably, and this complicates the comparison of reported results. Nonetheless, these studies do show that the preliminary general situation of CD prevalence in Russia seems to follow the general global tendencies.

$\mathrm{CD}$ is often diagnosed in the first year of life in children after introducing gluten-containing cereals into the mixed feeding. According to the recommendations of the Pediatric Union of Russian Federation it is preferable to introduce mixed feeding and in particular cereals at the age of 4-6 months. It is recommended to start a mixed feeding diet with the addition of gluten-free cereals such as rice and buckwheat, which is very popular in the Russian population, and later with maize. Then gluten-containing cereals can be included [33]. Thus, the first CD symptoms can be detected during early childhood. Indeed, all the data on CD incidence rates per Russian region is represented by children's cases (Table 2). Moreover, a considerable part of the studies that focus on CD prevalence in Russia were obtained from children (Table 3). Comparable data on CD prevalence in children and in adults only exists for the Irkutsk region, where a higher CD prevalence was reported in children than in adults (Table 3) [34]. Environmental factors influencing infancy or CD latency in adulthood can explain this fact [35].

The data on the incidence rate per region population (Table 2) shows that CD prevalence in Russia is increasing by up to $0.3 \%$. Nonetheless, it is obvious that this is an underestimation and not a true reflection of the incidence of the disease. Thus, the screening data on CD prevalence in schoolchildren and healthy blood donors studied in Russia varies by up to $0.6 \%$ (Table 3 ). These results follow the global tendencies presented in the literature for these categories of cohorts studied in various countries of Europe, America, and Southwest Asia [36-38].

CD prevalence among the population of the specific risk groups studied in Russia varied from approximately 1\% up to $16 \%$ (Table 3 ). Unfortunately, the recruitment procedures for the patients involved in these studies were too briefly described in the original papers, which makes the comparison of the results with other studies even more difficult. Nonetheless, these results are comparable with the results from a number of studies that focus on the assessment of CD prevalence in different risk groups from distinct countries reporting $\mathrm{CD}$ prevalence for risk groups, which are 2-10 fold in comparison to the CD prevalence found among the entire populations $[36,39,40]$.

Results on CD incidence (Table 2) and prevalence in the different regions of Russia obtained for children cohorts (Table 3) revealed no clearly differentiated gender-related dependence. These data are in contradiction with welldocumented general female dominance among CD patients [41] and can be explained by the peculiarities of the patients' recruitment among the children falling into the specific risk groups (Table 3). Nonetheless, the higher prevalence of CD in adult women was registered (Table 3 ), which is in accordance 


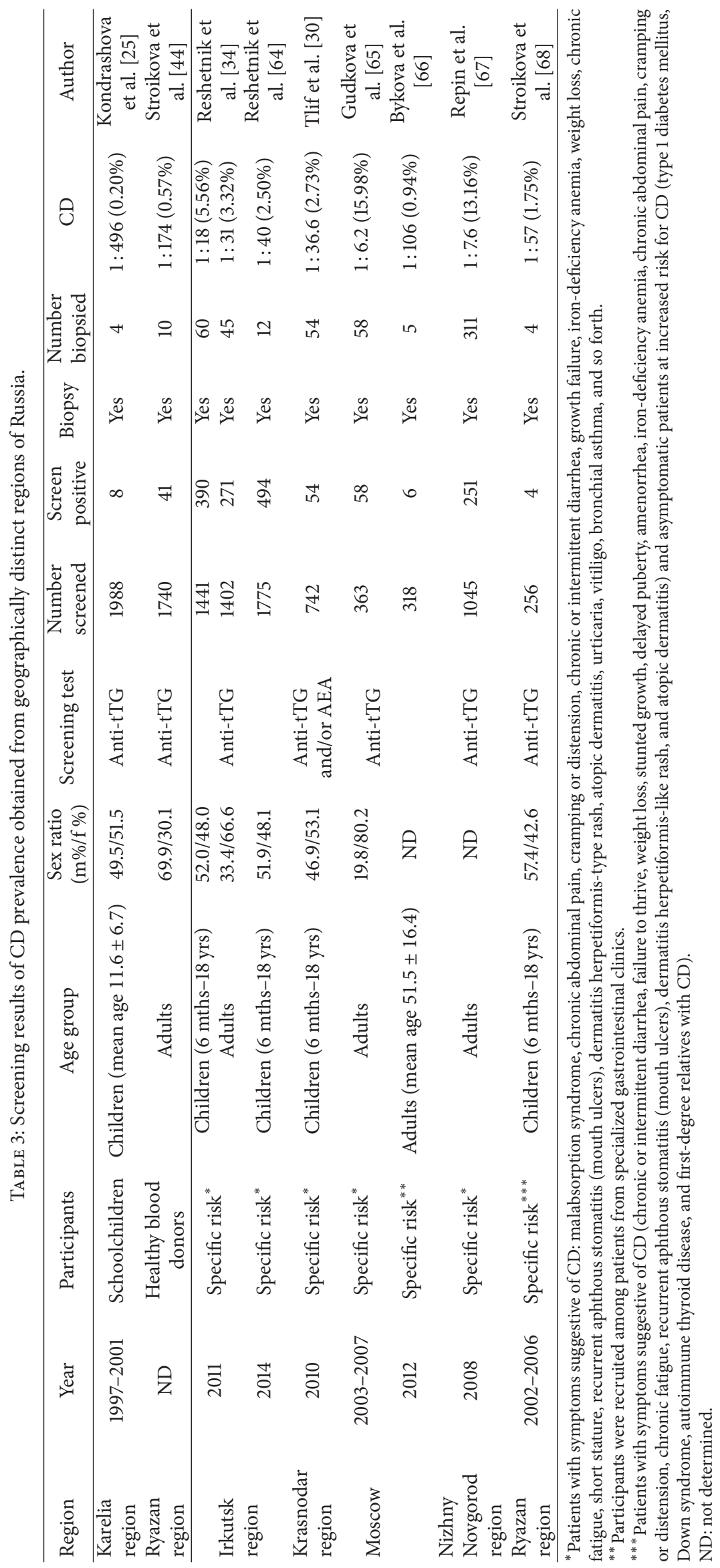


with other studies from other locations [42, 43]. Female dominance among $\mathrm{CD}$ patients is usually explained by the deficiency in healthcare services or hormonal differences between genders $[42,43]$. Conversely, the higher prevalence of $\mathrm{CD}$ in men among blood donors can be explained by the bias towards men in the cohort of subjects involved in the study [44].

To date, studies on polymorphic variants of HLA DQA1 and DQB1 genes in CD patients have only been performed in three regions in Russia (Tomsk, Krasnodar, and Yakutia) [30-32]. Indeed, genotypes of CD patients in different regions have their own characteristics and the absence of certain alleles does not exclude the possibility of the development of the disease. It was found that the incidence of susceptibility alleles HLA-DQ2 and/or HLA-DQ8 in several regions of Russia is significantly lower than in Europe (approximately $80 \%$ versus $>90 \%$ ) $[45,46]$. Remarkably, in Kazakhstan the frequency of these susceptibility alleles in $\mathrm{CD}$ patients was reported as being even lower than in mentioned regions of Russia (approximately 60\%) [28]. It is well-documented that frequency of susceptibility alleles in Caucasian populations in Western Europe has been estimated at 20-30\%. Relatively high frequencies also occur in Northern and Western Africa, the Middle East, and central Asia, whereas high frequencies of susceptibility alleles decline from West to East with low frequencies in populations in Southeast Asia and the virtual absence of DQ2 in Japan [47]. Thus, one could speculate that the lower frequency of these alleles in the patients from several regions of Russia and, especially, in patients from Kazakhstan is a result of the lower frequency of these alleles in the general populations of these regions.

The haplotypes of genetic susceptibility to CD HLADQ2 (DQA1* 05, DQB1 ${ }^{*} 02$ ) found in patients from Russian regions $[30,31]$ are consistent with those in Europe [48]. Relatively high frequencies for HLA-DQ8 (DQA ${ }^{*} 03$, DQB1* 03$)(\sim 30 \%)$ detected in patients from Yakutia [32] can be explained by the low number of patients involved in the study and/or by the specific features of the study, in which both Caucasians and Mongoloid subjects were recruited. Nevertheless, due to the low number of patients involved in the studies in Russia the incidence of polymorphic variants of HLA DQA1 and DQB1 genes in CD patients needs to be studied further.

One could speculate that, by comparing the results from one Russian region (Karelia; $0.2 \%$ ) with Finland (0.9\%), the low CD prevalence in Russia is explainable by the poorer living conditions and hygiene standard [25]. However, the comparison of available data on the average frequency of CD distribution in Russia (Table 3), with its distribution in European countries (e.g., $0.3 \%$ in Germany, $0.7 \%$ in Italy, and $1.8 \%$ in Sweden $[49,50])$, shows comparable results, which makes such a speculation unlikely.

\section{Support for CD Patients in Russia}

Celiac patients in Russia are registered as chronic patients and undergo medical checkups once every 6 months (after diagnosis within the first two years) or 12 months (the third year of observation subject to the establishment of stable remission). On a Federal level, there is social support (free set of gluten-free products) for children diagnosed with "celiac disease" [51]. In some regions, children with CD (but without a status of disabled person) receive social support from the regional governments (monthly grants) [52].

In addition, in Russia few local associations exist for patients with celiac disease designed to implement different projects aimed at social support and improving the quality of life of people following a strict gluten-free diet (GFD). They keep web pages that disseminate information about CD and various events for $\mathrm{CD}$ patients, with people needing to follow GFD [53-55].

Gluten-free products may be purchased in specialized shops, e-shops, or some supermarkets, and the list of glutenfree products is gradually expanding. Novel gluten detoxification enzymatic tools are under development [56].

\section{Conclusions}

The present data on CD prevalence in Russia may give us some notion about the gluten intolerance situation in the country. As shown the average CD frequency in the general Russian population is about $0.2-0.6 \%$. However, the real rate is still unknown due to the absence of true diagnostic data from all the citizens. The presented Russian CD prevalence values can be well-explained by the "celiac iceberg" concept, and, for this reason, we believe that large-scale diagnostic screening covering all the major regions of Russia following certain criteria will clarify the true situation about glutenrelated diseases and, in particular, $\mathrm{CD}$.

\section{Competing Interests}

The authors declare that they have no competing interests.

\section{Acknowledgments}

The authors are very grateful to Jonathan McFarland for his editorial work throughout the preparation of this manuscript. This research was funded by the Russian Science Foundation (Grant no. 16-15-10410).

\section{References}

[1] A. Fasano and C. Catassi, "Celiac disease," New England Journal of Medicine, vol. 367, no. 25, pp. 2419-2426, 2012.

[2] C. Escudero-Hernández, A. S. Peña, and D. Bernardo, "Immunogenetic pathogenesis of celiac disease and non-celiac gluten sensitivity," Current Gastroenterology Reports, vol. 18, no. 7, article 36, 2016.

[3] I. Comino, M. De Lourdes Moreno, and C. Sousa, "Role of oats in celiac disease," World Journal of Gastroenterology, vol. 21, no. 41, pp. 11825-11831, 2015.

[4] A. Balakireva and A. Zamyatnin, "Properties of gluten intolerance: gluten structure, evolution, pathogenicity and detoxification capabilities," Nutrients, vol. 8, no. 10, article 644, 2016.

[5] L. V. Savvateeva and A. A. Zamyatnin, "Prospects of developing medicinal therapeutic strategies and pharmaceutical design for 
effective gluten intolerance treatment," Current Pharmaceutical Design, vol. 22, no. 16, pp. 2439-2449, 2016.

[6] E. Lionetti, S. Gatti, A. Pulvirenti, and C. Catassi, "Celiac disease from a global perspective," Best Practice and Research: Clinical Gastroenterology, vol. 29, no. 3, pp. 365-379, 2015.

[7] R. F. A. Logan, "Problems and pitfalls in epidemiological studies of coeliac disease," in Common Food Intolerances 1: Epidemiology of Coeliac Disease (Dynamic Nutrition Research) (Pt 1), S. Auricchio and J. K. Visakorpi, Eds., pp. 14-24, Karger, Basel, Swizerland, 1992.

[8] C. Catassi, I.-M. Rätsch, E. Fabiani et al., "Coeliac disease in the year 2000: exploring the iceberg," The Lancet, vol. 343, no. 8891, pp. 200-203, 1994.

[9] A. Fasano and C. Catassi, "Current approaches to diagnosis and treatment of celiac disease: an evolving spectrum," Gastroenterology, vol. 120, no. 3, pp. 636-651, 2001.

[10] S. Husby, S. Koletzko, I. R. Korponay-Szabó et al., "ESPGHAN Working Group on Coeliac Disease Diagnosis; ESPGHAN Gastroenterology Committee; European Society for Pediatric Gastroenterology, Hepatology, and Nutrition. European Society for Pediatric Gastroenterology, Hepatology, and Nutrition guidelines for the diagnosis of coeliac disease," Journal of Pediatric Gastroenterology and Nutrition, vol. 54, pp. 136-160, 2012.

[11] J. C. Bai, M. Fried, G. R. Corazza et al., "World gastroenterology organisation global guidelines on celiac disease," Journal of Clinical Gastroenterology, vol. 47, no. 2, pp. 121-126, 2013.

[12] J. F. Ludvigsson, J. C. Bai, F. Biagi et al., "Diagnosis and management of adult coeliac disease: guidelines from the British society of gastroenterology," Gut, vol. 63, no. 8, pp. 1210-1228, 2014.

[13] A. Rubio-Tapia, I. D. Hill, C. P. Kelly, A. H. Calderwood, and J. A. Murray, "ACG clinical guidelines: diagnosis and management of celiac disease," American Journal of Gastroenterology, vol. 108, no. 5, pp. 656-676, 2013.

[14] A. I. Parfenov, I. G. Maev, A. A. Baranov et al., "Russian consensus on the diagnosis and treatment of celiac disease in children and adults," Consilium Medicum, no. 2, pp. 86-90, 2016 (Russian).

[15] A. Rostom, J. A. Murray, and M. F. Kagnoff, "Medical position statement on celiac disease," Gastroenterology, vol. 131, pp. 19771980, 2006.

[16] D. Leffler, S. Saha, and R. J. Farrell, “Celiac disease," American Journal of Managed Care, vol. 9, no. 12, pp. 825-831, 2003.

[17] M. Silano, U. Volta, A. D. Vincenzi, M. Dessì, and M. D. Vincenzi, "Effect of a gluten-free diet on the risk of enteropathyassociated T-cell lymphoma in celiac disease," Digestive Diseases and Sciences, vol. 53, no. 4, pp. 972-976, 2008.

[18] A. S. Louka and L. M. Sollid, "HLA in coeliac disease: unravelling the complex genetics of a complex disorder," Tissue Antigens, vol. 61, no. 2, pp. 105-117, 2003.

[19] I. Ricaño-Ponce, C. Wijmenga, and J. Gutierrez-Achury, "Genetics of celiac disease," Best Practice \& Research Clinical Gastroenterology, vol. 29, no. 3, pp. 399-412, 2015.

[20] R. Dieli-Crimi, M. C. Cénit, and C. Núñez, “The genetics of celiac disease: a comprehensive review of clinical implications," Journal of Autoimmunity, vol. 64, pp. 26-41, 2015.

[21] F. Megiorni and A. Pizzuti, "HLA-DQA1 and HLA-DQB1 in Celiac disease predisposition: practical implications of the HLA molecular typing," Journal of Biomedical Science, vol. 19, no. 1, pp. 88-92, 2012.
[22] D. A. Leffler and D. Schuppan, "Update on serologic testing in celiac disease," American Journal of Gastroenterology, vol. 105, no. 12, pp. 2520-2524, 2010.

[23] G. Oberhuber, G. Granditsch, and H. Vogelsang, "The histopathology of coeliac disease: time for a standardized report scheme for pathologists," European Journal of Gastroenterology and Hepatology, vol. 11, no. 10, pp. 1185-1194, 1999.

[24] C. Catassi and A. Fasano, "Coeliac disease: the debate on coeliac disease screening-are we there yet?" Nature Reviews Gastroenterology and Hepatology, vol. 11, no. 8, pp. 457-458, 2014.

[25] A. Kondrashova, K. Mustalahti, K. Kaukinen et al., "Lower economic status and inferior hygienic environment may protect against celiac disease," Annals of Medicine, vol. 40, no. 3, pp. 223-231, 2008.

[26] Russian Scientific Electronic Library, “eLIBRARY.RU," http://elibrary.ru/.

[27] Russian Scientific Electronic Library, “Cyberleninka," http://cyberleninka.ru.

[28] M. N. Sharipova, "Clinical, epidemiological and genetic characteristics of celiac disease in children in Kazakhstan," Pediatria Named after G.N. Speransky, vol. 87, pp. 106-108, 2009 (Russian).

[29] A. T. Kamilova, M. N. Ahmedov, and Z. M. Abduzhabbarova, "Status of medico-social rehabilitation of children with disabilities in Uzbekistan on the example of children with celiac disease," in Proceedings of the XIII Congress of Pediatric Gastroenterologists: Actual Problems of Abdominal Pathology in Children, V. A. Tabolin, Ed., pp. 313-314, Medpraktika, 2006.

[30] A. I. Tlif, E. I. Kondratyeva, I. Y. Chernyak, O. V. Dolbneva, I. I. Shtoda, and I. M. Golovenko, "The prevalence of polymorphisms of genes HLA DQA1 and DQB1 in patients with type 1 diabetes and celiac disease in the Krasnodar Region," Kuban Scientific Medical Bulletin, vol. 5, pp. 65-69, 2012 (Russian).

[31] E. I. Kondratyeva and G. N. Yankina, "Incidence of polymorphic variants of HLA DQA1 and DQB1 genes in patients with celiac disease in Tomsk and Krasnodar," Pediatric Nutrition, vol. 10, pp. 11-14, 2012 (Russian).

[32] H. A. Kurtanov, A. L. Danilova, A. E. Yakovleva, A. D. Savvina, and H. P. Maximova, "Genetic research of HLA genes I and II class-DRB1, DQA1, DQB1 in patients with celiac disease," The Bulletin of Hematology, vol. 11, pp. 44-47, 2015 (Russian).

[33] National Program for Infants Feeding Optimization in the Russian Federation, Moscow, Russia, 2011.

[34] L. A. Reshetnik and O. V. Antsiferova, "Celiac Disease. Results serological screening of the population in Irkutsk region," Siberian Medical Journal, vol. 8, pp. 79-81, 2011 (Russian).

[35] M. Mariné, C. Farre, M. Alsina et al., "The prevalence of coeliac disease is significantly higher in children compared with adults," Alimentary Pharmacology and Therapeutics, vol. 33, no. 4, pp. 477-486, 2011.

[36] J. F. Ludvigsson, T. R. Card, K. Kaukinen et al., "Screening for celiac disease in the general population and in high-risk groups," United European Gastroenterology Journal, vol. 3, no. 2, pp. 106-120, 2015.

[37] A. Fasano, I. Berti, T. Gerarduzzi et al., "Prevalence of celiac disease in at-risk and not-at-risk groups in the United States: a large multicenter study," Archives of Internal Medicine, vol. 163, no. 3, pp. 286-292, 2003.

[38] P. Singh, S. Arora, A. Singh, T. A. Strand, and G. K. Makharia, "Prevalence of celiac disease in Asia: a systematic review and 
meta-analysis," Journal of Gastroenterology and Hepatology, vol. 31, no. 6, pp. 1095-1101, 2016.

[39] Z. Vančíková, V. Chlumecký, D. Sokol et al., “The serologic screening for celiac disease in the general population (blood donors) and in some high-risk groups of adults (patients with autoimmune diseases, osteoporosis and infertility) in the Czech Republic preliminary report," Folia Microbiologica, vol. 47, no. 6, pp. 753-758, 2002.

[40] J. A. Murray, "Celiac disease in patients with an affected member, type 1 diabetes, iron-deficiency, or osteoporosis?" Gastroenterology, vol. 128, no. 4, pp. S52-S56, 2005.

[41] E. Roma, J. Panayiotou, H. Karantana et al., "Changing pattern in the clinical presentation of pediatric celiac disease: a 30-year study," Digestion, vol. 80, no. 3, pp. 185-191, 2009.

[42] M. J. Llorente-Alonso, M. J. Fernández-Aceñero, and M. Sebastián, "Gluten intolerance: sex- and age-related features," Canadian Journal of Gastroenterology, vol. 20, no. 11, pp. 719$722,2006$.

[43] T. van Gils, B. Rootsaert, G. Bouma, and C. J. Mulder, "Celiac disease in The Netherlands: demographic data of members of the Dutch Celiac Society," Journal of Gastrointestinal and Liver Diseases, vol. 25, no. 4, pp. 441-445, 2016.

[44] M. Stroikova, N. Augul, J. Gureev et al., "Screening of blood donors for tissue transglutaminase antibodies in the Ryazan area (Russia)," Digestive and Liver Disease, vol. 38, no. 8, pp. 617619, 2006.

[45] K. Karell, A. S. Louka, S. J. Moodie et al., "HLA types in celiac disease patients not carrying the $D Q A 1^{*} 05-D Q B 1^{*} 02$ (DQ2) heterodimer: results from the European genetics cluster on celiac disease," Human Immunology, vol. 64, no. 4, pp. 469-477, 2003.

[46] F. Fernández-Bañares, B. Arau, R. Dieli-Crimi, M. Rosinach, C. Nuñez, and M. Esteve, "Systematic review and meta-analysis show $3 \%$ of patients with celiac disease in Spain to be negative for HLA-DQ2.5 and HLA-DQ8," Clinical Gastroenterology and Hepatology, 2016.

[47] A. G. Cummins and I. C. Roberts-Thomson, "Prevalence of celiac disease in the Asia-Pacific region," Journal of Gastroenterology and Hepatology, vol. 24, no. 8, pp. 1347-1351, 2009.

[48] E. C. De Haas, V. Kumar, and C. Wijmenga, "Immunogenetics of celiac disease," in Clinical Gastroenterology, S. Devi and G. E. Mullin, Eds., pp. 1-16, Humana Press, Totowa, NJ, USA, 2013.

[49] K. Mustalahti, C. Catassi, A. Reunanen et al., "The prevalence of celiac disease in Europe: results of a centralized, international mass screening project," Annals of Medicine, vol. 42, no. 8, pp. 587-595, 2010.

[50] A. Myléus, A. Ivarsson, C. Webb et al., "Celiac disease revealed in 3\% of Swedish 12-year-olds born during an epidemic," Journal of Pediatric Gastroenterology and Nutrition, vol. 49, no. 2, pp. 170-176, 2009.

[51] Ministry of Health and Social Development of the Russian Federation, Administrative Order No.1 of 9 January 2007.

[52] "On the introduction of amendments into individual legislative acts of the Russian Federation in connection with an improvement in the demarcation of powers," Federal Law of Russian Federation no. 230-fz from 2007.

[53] Saint-Petersburg coeliac society, http://www.celiac.spb.ru.

[54] Gluten-free Guide, http://www.glutenfreerussia.ru.

[55] “Tomsk Regional Public Organization Siberian Center for support of patients with celiac disease and cystic fibrosis," http:// www.sibceliac.narod.ru.
[56] L. V. Savvateeva, N. V. Gorokhovets, V. A. Makarov et al., "Glutenase and collagenase activities of wheat cysteine protease Triticain- $\alpha$ : feasibility for enzymatic therapy assays," International Journal of Biochemistry and Cell Biology, vol. 62, pp. 115124, 2015.

[57] G. P. Smirnova, A. V. Tyurikov, T. A. Shkuleva, and H. I. Barusheva, "Celiac disease in children of the Arkhangelsk region," Pediatric Nutrition, vol. 3, article 87, 2005 (Russian).

[58] V. N. Turchina and T. A. Tabak, "Celiac disease in children," in Guidance Manual, pp. 1-25, Ural State Medical Academy of Additional Education, Chelyabinsk, Russia, 2004 (Russian).

[59] N. V. Savvina, A. D. Savvina, G. M. Melchanova, and N. N. Gryaznukhina, "Organization of dynamic observation of children with celiac disease," Far East Medical Journal, vol. 4, pp. 82-85, 2009 (Russian).

[60] I. V. Vasilkova, Medico-social and organizational problems of celiac disease [Ph.D. thesis in Medicine], Saint-Petersburg State Pediatric Medical University, Saint-Petersburg, Russia, 2004 (Russian).

[61] V. G. Klimin, L. N. Malamova, A. M. Cherednichenko, and S. V. Tetereva, "Celiac disease in children: solved and unsolved problems of organization of diagnostics and monitoring," in Proceedings of the 16th Congress of Pediatric Gastroenterologists of Russia and CIS: Actual Problems of Abdominal Pathology in Children, Y. G. Mukhina and S. V. Belmer, Eds., pp. 321-322, Medpraktika, Moscow, Russia, 2009 (Russian).

[62] G. N. Yankina, Clinical-genetic and immuno-morphological aspects of celiac disease in children. The strategy of rehabilitation [DSc thesis in Medicine], Siberian State Medical University, Tomsk, Russia, 2014 (Russian).

[63] A. D. Savvina, N. V. Savvina, and O. V. Nozhnova, "Dispensary observation of patients with celiac disease in Yakutsk," in Republican Research-to-Practice Conference: Actual Problems of Pediatrics and Pediatric Surgery, pp. 83-86, Publishing House of Yakutsk, Yakutsk, Russia, 2009 (Russian).

[64] L. A. Reshetnik, O. V. Antsiferova, T. A. Spasich, and S. S. Golubev, "Diagnosis of celiac disease in routine clinical practice," Pediatrician (St. Petersburg), vol. 5, no. 2, pp. 14-17, 2014 (Russian).

[65] R. B. Gudkova, L. M. Krums, V. B. Potapova, E. A. Sabel'nikova, B. Z. Chikunova, and A. I. Parfenov, "Specific immune response in diagnosis of celiac disease with chronic diarrhea," Experimental and Clinical Gastroenterology, no. 5, pp. 47-52, 2009 (Russian).

[66] S. V. Bykova, E. A. Sabelnikova, R. B. Gudkova et al., "Celiac disease detection rate in gastroenterological patients," Terapevticheskii Arkhiv, vol. 88, pp. 39-43, 2016 (Russian).

[67] A. A. Repin, Y. A. Bogdarin, B. V. Sarantsev, O. V. Teplov, N. V. Desyatnikova, and A. I. Parfenov, "Prevalence of celiac disease in risk group patients in Nizhny Novgorod region," Terapevticheskii Arkhiv, vol. 80, no. 2, pp. 38-44, 2008.

[68] M. V. Stroikova, V. G. Demikhov, S. K. Borisova et al., "Significance of evaluation of IgA antibodies to tissue transglutaminase for the diagnosis of celiac disease," Pediatric Hematology/Oncology and Immunopathology, vol. 5, pp. 32-35, 2006 (Russian). 


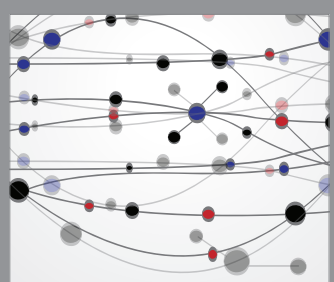

The Scientific World Journal
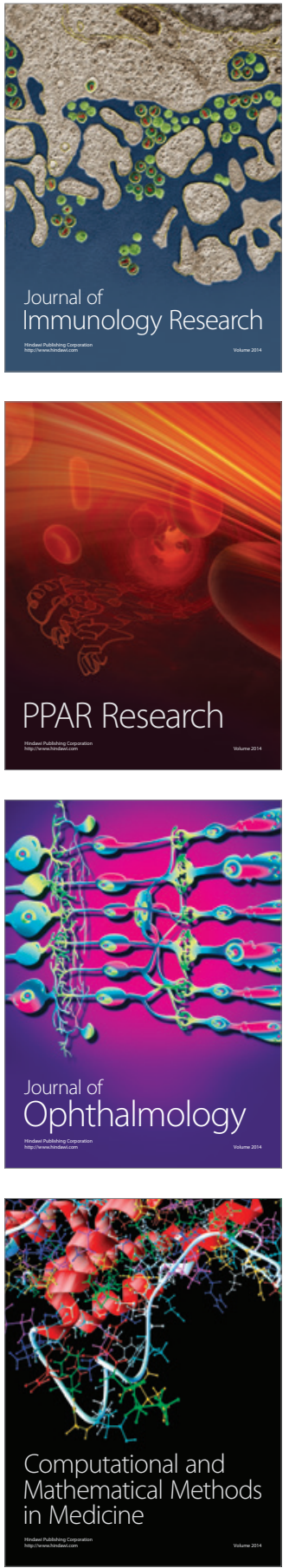

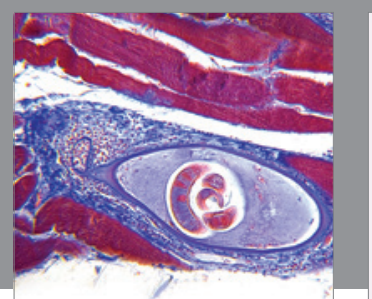

Gastroenterology Research and Practice
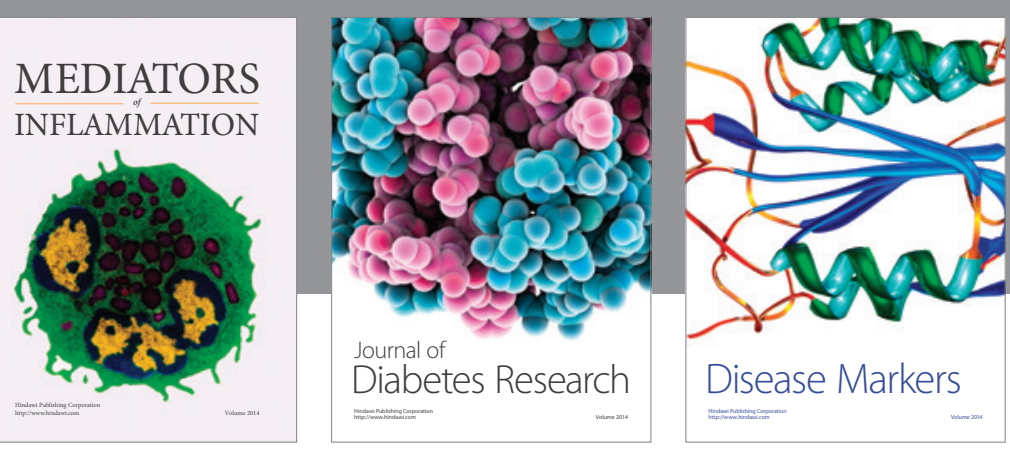

Disease Markers

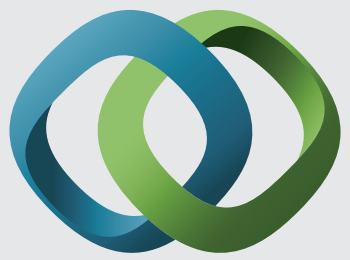

\section{Hindawi}

Submit your manuscripts at

https://www.hindawi.com
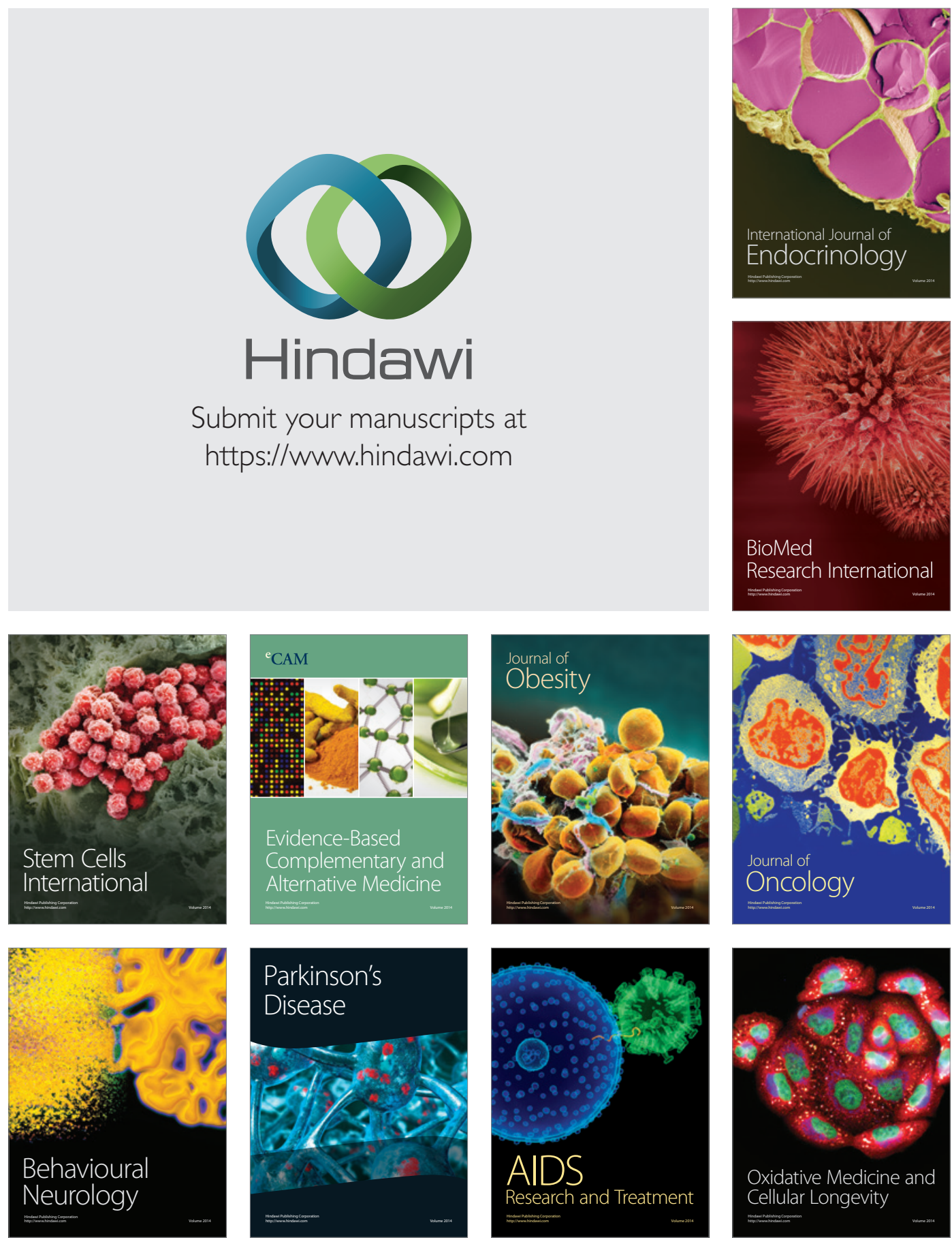